\title{
11 | Interrogating China's biotechnology revolution: contesting dominant science policy cultures in the risk society
}

\author{
JAMES KEELEY
}

\section{Introduction}

Laboratories around the country are aiming their gene guns at pig and goat cells in the hope of developing pharmaceutical proteins and transplantable organs for humans or injecting pollen grains with DNA to produce virusresistant papayas, potatoes, tobacco and tomatoes. One man is working on cloning the fast-disappearing panda. (Smith 2000)

China has the fourth-largest area sown to genetically modified (GM) crops in the world. It plans to spend over US\$500 million annually on agribiotechnology research by 2004, overtaking the USA. It has developed a host of different GM plants engineered for a range of different traits (Huang et al. 2002a, 2002b; Huang and Wang 2003; Keeley 2003a). China decoded the rice genome largely independent of the West. The country's biotechnology revolution appears to be well on course, leaving other developing countries, not to mention many industrialized nations, in the starting blocks.

An important aspect of China's biotechnology achievements is the way they are manipulated in the global propaganda war enveloping GM crops. China, for the advocates, shows the way forward for developing countries. It understands what the twenty-first-century knowledge economy is about and it shows what can be done if there are no troublesome non-governmental organizations (NGOs) panicking farmers and consumers (see, e.g., Paarlberg 2001). In January 2002, an article documenting China's GM achievements was published in the journal Science (Huang et al. 2002a). Publication demonstrated, first, that what is happening in China is taken seriously by the international scientific establishment, and second - as became evident through related e-mail and newspaper discussion - that China is key to the global GM project. It is a winner: it shows that GM is working, and farmers like the products. Critically, it shows that a state can harness the power of biotechnology for developmental ends. As an official from the International Service for Acquisition of Agribiotechnology Applications asserted: 'The Chinese experience amply demonstrates the multifold and significant benefits that appropriate transgenic technology or transgenic crops can deliver to the society and to farmers as a whole.' ${ }^{1}$ 
This chapter challenges these narratives about genetic engineering in China. It argues that the picture often painted in the global and Chinese media and through corporate information sources is actually a misrepresentation of the Chinese biotechnology story. The argument is made in two stages. The first part of the chapter explores how the Chinese experience differs from what has happened elsewhere. It is argued that biotechnology in China has been effective in achieving a remarkable amount quickly because the state has approached development in a particular way: targeting a priority area and channelling investment to promote rapid technological innovation. This has been assisted by dense networks of hybrid policymakers, scientists and businesspeople funding, researching, developing, commercializing and regulating technologies.

The Chinese state has a distinctive approach to development that resonates with that of other East Asian states governing the market and delivering rapid industrialization in the 1970s and 1980s (see Blecher and Shue 1996; Duckett 1998; Evans 1995; Kang 2002; Wade 1990; White 1988; World Bank 1993). In this, the state delivers public goods, and allows the private sector to operate in a way that does not undermine this provision. The state shapes markets, and directs and controls capital towards particular policy ends. This model of the state entails a particular vision of the Chinese citizen, in which citizenship is perceived less in terms of claiming and exercising individual rights, as in liberal-democratic traditions, but more in terms of enjoyment of social and economic benefits granted by the state. This idea of citizenship emphasizes the collective more than the individual; the social and economic benefits the state provides are realized only through active engagement in a collective project. Of course, this narrative has been modified as the famous iron rice bowl has cracked and broken, reflected in the encouragement of more entrepreneurial and selfreliant forms of citizenship, and as official narratives of the citizen come to be debated in the media and elsewhere (Anagnost 1997; Barme 1999; Keane 2001; Parris 1999). Biotechnology is part of the vision of the state delivering modernization for its citizens, with the collective benefiting from the development and application of science and technology.

The second part of the chapter explores the way in which 'risk society' debates make this application of the state-governed development model look problematic. Following Beck (1992) and Giddens (1990), many new technologies associated with late modernity, such as the life sciences, create unanticipated and unwanted effects while simultaneously being set to ameliorate other perceived social problems. What these debates identify as risk is inherently embedded in industrialization and modernization, and the risk society is in this sense a new phenomenon demanding new 
institutional responses, including principally a capacity to act reflexively. For many, given the social nature of risk - who decides what counts as a benefit or cost? how are probabilities assessed? - and the inherent difficulty of managing uncertainty, let alone the embedded social meanings of technological trajectories more broadly, this can be possible only through deliberation between multiple perspectives and values.

The Chinese case is interesting because China has gone about biotechnology as if it were any other aspect of the socialist modernization that it has undertaken so well in the past; in health systems or rural infrastructure, for example. Chinese society and China's place in the world have changed fundamentally, however. China is now highly integrated with the global economy and has an increasingly well-educated and critical citizenry. In relation to biotechnology, this means that the science policy cultures that have delivered change at unprecedented rates are increasingly being challenged. In the past, it appeared possible to some extent to evade doubt, uncertainty and ignorance. Now, suddenly, China has to engage with multifarious articulations of risk and, implicitly, new notions of citizenship. Bureaucrats themselves are embedded in a different global policy, electronic and professional networks (Breslin 2003; Lynch 1999). Diverse risks - from trade shocks to lack of consumer acceptance and unanticipated environmental impacts - have posed fundamental challenges to the state's approach to biotechnology and development. In this respect, the basic sense of coherence, organization and purpose that made Chinese endeavours so effective can paradoxically be a source of weakness.

Given these dynamics, it becomes clear that the embrace of the biotechnology revolution is not as unequivocal as much global discourse suggests, nor is the biotechnology already commercialized in China the indisputable success that its advocates would like to claim. In reality, China presents a much more ambiguous picture, with wider implications for thinking about the potential contribution of biotechnology to development, food security and 'good ways of life' more generally.

\section{China's biotechnology achievements}

China's achievements in the biotechnology field have been considerable (Huang and Wang 2003; Keeley 2003a). By far the most important GM crop is $B t$ cotton, which was first approved for commercialization in 1997, with the severe bollworm crisis of the early 1990 s still a recent memory. It is now grown over an area of $1.5 \mathrm{~m}$ hectares (in 2001), which amounts to 35 per cent of the cotton area, in several different provinces. ${ }^{2}$ In the northern provinces around the Yellow River, take-up is reckoned to be over 95 per cent (Huang et al. 2003). 